\title{
Streptococcus mutans
}

National Cancer Institute

\section{Source}

National Cancer Institute. Streptococcus mutans. NCI Thesaurus. Code C124411.

A species of Gram-positive coccus-shaped bacteria in the order Lactobacillales. S.

mutants is commonly found in the human oral cavity, where is a primary causative agent

of tooth decay. 